\title{
CORRELAÇÃO ENTRE A CAPACIDADE PROLIFERATIVA IN VITRO E A DOMINÂNCIA APICAL IN VIVO DA BANANEIRA cvs. GRAND NAINE E NANICÃO ${ }^{1}$
}

\author{
CLAYTON DEBIASI ${ }^{2}$, GILMAR ROBERTO ZAFFARI ${ }^{3}$, AIRTON RODRIGUES SALERNO ${ }^{3}$ \\ MIGUEL PEDRO GUERRA ${ }^{4}$
}

\begin{abstract}
RESUMO- No presente trabalho, buscou-se correlacionar diferentes graus de dominância apical in vivo com a capacidade proliferativa in vitro da bananeira, através da relação existente entre a fonte de explante e o seu posterior comportamento in vitro. Brotos laterais de Musa acuminata Colla: Nanicão (AAA) e Grand Naine (AAA), oriundos de plantas-matrizes mostrando diferentes graus de dominância apical in vivo (elevada, média e baixa) foram cultivados in vitro, no Laboratório de Cultura de Tecidos Vegetais da EEI/ EPAGRI-SC, por cinco subcultivos, em intervalos de 30 dias, em meio MS suplementado com BAP (11,1 mmol/l), sacarose (30 g/l), ágar (7 g/l), vitaminas MS e pH 5,8. O grau de dominância apical in vivo influenciou diretamente o comportamento in vitro dos explantes, no que diz respeito à capacidade proliferativa. Brotos laterais oriundos de plantas-matrizes, com grau de dominância apical in vivo baixa, proporcionaram a maior taxa média proliferativa (7,5 brotos/explante) para a cv. Grand Naine, enquanto brotos laterais oriundos de plantas-matrizes com grau de dominância apical média proporcionaram a maior taxa média proliferativa (10,96 brotos/explante) para a cv. Nanicão.
\end{abstract}

Termos para indexação: Banana, dominância apical, micropropagação, Musa acuminata.

\section{IN VITRO PROLIFERATIVE CAPACITY AND IN VIVO APICAL DOMINANCE IN BANANA CVS. GRAND NAINE AND NANICÃO}

SUMMARY- In the present work aimed to study the correlation between the in vivo apical dominance and the in vitro regenerative capacity in banana (Musa acuminata Colla) cvs. Nanicão (AAA) and Grand Naine (AAA). Lateral buds explanted from mother plants showing different apical dominace levels (low, medium and high) were cultivated in the Laboratory of Tissue Culture of EEI/EPAGRI-SC, during five subcultures with 30 days interval in MS culture medium supplemented with BAP $(11,1 \mathrm{mmol} / \mathrm{l})$, sucrose $(30 \mathrm{~g} / \mathrm{l})$, agar $(7 \mathrm{~g} / \mathrm{l})$ and $\mathrm{MS}$ vitamins. The $\mathrm{pH}$ was adjusted to $5.8 \mathrm{prior}$ autoclaving. Cultures derived from lateral buds of mother plants showing low level of apical dominace resulted in the highest proliferation rate, with 7.5 shoots per explant for 'Grand Naine'. As for cv Nanicão the highest proliferation rate (10.9 shoots/explants) resulted from mother plants showing medium level of apical dominance.

Index terms: Apical dominance, banana, micropropagation, Musa acuminata.

\section{INTRODUÇÃO}

A aplicação das técnicas de micropropagação na bananeira depende da capacidade de alterar-se o processo de dominância apical. A principal hipótese associada a este evento é a de que as auxinas, sintetizadas na gema apical de crescimento, transportadas basipetalmente e acumulando-se nas gemas laterais, inibiriam o seu desenvolvimento (Tamas, 1995; Mantedioca, 1996).

Observando-se o comportamento in vivo e in vitro da bananeira, nota-se que a capacidade proliferativa apresenta uma alta variação, sugerindo uma associação destes eventos com a dominância apical.

A propagação in vivo da bananeira propicia um limitado número de mudas, além de possibilitar a disseminação de pragas e doenças. A micropropagação depende, em grande parte, do crescimento das gemas laterais dos explantes, controlado pelo meristema apical (Cline, 1997). Assim, vários trabalhos foram conduzidos visando a estabelecer protocolos seguros e que propiciem uma alta taxa proliferativa in vitro da bananeira (Angarita \& Perea, 1991; Sandoval et al., 1991).

Dentre os diversos fatores relacionados à micropropagação, $\mathrm{o}$ explante, no que diz respeito a fonte, tipo, tamanho, fase e manejo empregado, exerce forte influência nas subseqüentes respostas obtidas in vitro (Zaffari et al., 1995).

O objetivo deste trabalho foi o de correlacionar diferentes níveis de dominância apical in vivo à capacidade proliferativa in vitro da bananeira, através da relação existente entre a fonte de explante e o seu posterior comportamento in vitro, visando à otimização de protocolos regenerativos nesta espécie. Buscou-se também uma maior compreensão dos aspectos fisiológicos e morfológicos envolvidos no processo de formação de brotos laterais.

\section{MATERIALEMÉTODOS}

Material vegetal

Plantas-matrizes das cultivares Nanicão (AAA) e Grand Naine (AAA), com idade aproximada de um ano, mantidas a campo no banco de germoplasma da Estação Experimental de Itajaí/Empresa de Pesquisa e Extensão Rural de Santa Catarina S.A. (EEI/EPAGRI-SC), foram avaliadas quanto aos graus de dominância apical em que se encontravam, registrando-se o número de brotos laterais emitidos por planta-matriz e dos quais foram obtidas as gemas laterais que serviram como explantes iniciais aos processos de estabelecimento e cultivo in vitro, formandose, assim, os diferentes tratamentos: 1) Gemas laterais oriundas de plantas com Elevada dominância apical (um broto lateral por planta-matriz); 2) Gemas laterais oriundas de plantas com Média dominância apical (5 a 6 brotos laterais por planta-matriz); e 3) Gemas laterais oriundas de plantas com Baixa dominância apical (10 a 15 brotos laterais por plantamatriz).

\section{Estabelecimento e cultura in vitro}

As culturas in vitro foram estabelecidas no Laboratório de Cultura de Tecidos Vegetais da EEI/ EPAGRI-SC, localizado no município de Itajaí-SC. Em câmara de fluxo laminar, as gemas laterais foram submetidas a uma desinfestação em solução de hipoclorito de sódio comercial a $33 \%(\mathrm{v} / \mathrm{v})$ adicionada de algumas gotas de detergente neutro por 20 minutos e, em seguida, com álcool a 70\%, por 2 minutos. Posteriormente, este material foi reduzido a um tamanho aproximado de $5 \times 5 \times 10$ mm e transferido para tubos de ensaio contendo meio de cultura de Murashige \& Skoog (1962) (MS), suplementado com ácido indol-3acético (AIA) (5,71 mmol/l) e benzilaminopurina (BAP) $(4,44 \mathrm{mmol} / \mathrm{l})$. Após 60 dias de cultivo, as gemas foram transferidas para o meio de proliferação, constituído pela formulação MS suplementado com BAP

1 (Trabalho 056/2002). Recebido: 04/01/2001. Aceito para publicação: 25/06/2002.

2 Pesquisador do Laboratório de Biotecnologia/Micropropagação Vegetal, FURB, Caixa Postal 1507, 89010-971, Blumenau-SC. Fone (047) 321-0436. E-mail debiasi@furb.br

3 Pesquisador do Laboratório de Cultura de Tecidos, Estação Experimental de Itajaí, EPAGRI, Caixa Postal 277,88301-970, Itajaí-SC, Brasil. Fone (047) 346-5244.

4 Pesquisador do Laboratório de Fisiologia do Desenvolvimento e Genética Vegetal, PGRGV/UFSC, Caixa postal 476, 88.040-900, Florianópolis-SC, Brasil. Fone (048) $331-5331$ 
$(11,1 \mathrm{mmol} / \mathrm{l})$. A estes meios de cultura, adicionaram-se $30 \mathrm{~g} / \mathrm{l}$ de sacarose, $7 \mathrm{~g} / \mathrm{l}$ de ágar e vitaminas MS. O pH foi ajustado para 5,8 antes da autoclavagem. As culturas foram mantidas em câmara de crescimento sob um fotoperíodo de 16 horas de luz, intensidade luminosa de 50 mmol. $\mathrm{m}^{-2} \cdot \mathrm{s}^{-1} \mathrm{e}$ temperatura de $28 \pm 2^{\circ} \mathrm{C}$. As culturas foram subcultivadas cinco vezes, em intervalos de 30 dias, individualizando-se as brotações laterais emitidas por explante único.

\section{Aclimatização}

A aclimatização constou da individualização e limpeza das mudas micropropagadas em água corrente e o plantio posterior em tubetes contendo substrato ( $1 / 2$ subsolo e $1 / 2$ casca de arroz carbonizada), sendo então mantidas em telados cobertos com sombrite, com redução da radiação solar em $70 \%$, permanecendo por um período aproximado de 30 a 40 dias na fase de adaptação.

\section{Avaliações e análises dos resultados}

Os parâmetros avaliados foram:

1) Capacidade de proliferação in vitro, através da contagem do número de brotos laterais emitidos por explante único a cada subcultivo realizado;

2) Altura média dos brotos, pela medição individual das brotações emitidas a cada subcultivo, com auxílio de régua acrílica desinfestada com solução de hipoclorito de sódio a $3 \%$ e álcool $70 \%$; e;

3) Fenótipo das plantas micropropagadas, enfatizando o aparecimento de variação somaclonal (dos tipos anão e variegado) através de avaliações visuais.

O experimento foi conduzido em um delineamento experimental inteiramente casualizado, com doze repetições por tratamento, e uma planta por parcela. As análises dos dados experimentais foram baseadas na Análise da Variância (ANOVA) e no teste de separação de médias (Tukey 5\%).

\section{RESULTADOS E DISCUSSÃO}

O presente estudo da correlação existente entre a dominância apical in vivo e a capacidade proliferativa in vitro da bananeira cvs. Grand Naine e Nanicão revelou diferenças significativas tanto no grau de dominância apical da planta-mãe (Figura 01), quanto no seu posterior comportamento in vitro (Figuras 02 e 03 e Tabelas 01 e 02).

Observou-se um efeito estimulatório, tanto nos cultivos dos tratamentos com baixa dominância apical, quanto nos de média dominância apical. O número médio de brotos por explante de bananeira regenerados in vitro foi crescente para ambas as cvs. até o terceiro subcultivo, apresentando uma redução subseqüente em todos os tratamentos até o último subcultivo. As maiores taxas médias proliferativas foram de 7,51 brotos no tratamento com baixa dominância apical para a cv. Grand Naine e de 10,96 brotos no tratamento com média dominância apical para a cv. Nanicão, ambas no terceiro subcultivo (120 dias). Estes resultados são similares aos reportados por Banerjee \& De Langhe (1985), Oliveira \& Silva (1997) e Oliveira et al. (1999), que obtiveram as maiores taxas de multiplicação no terceiro ou no quarto subcultivo.

A influência da fonte de explante no comportamento in vitro da cv. Robusta foi relatada por Lameira et al. (1988). Estes autores verificaram que a utilização de explantes originados de ápices caulinares com folhas jovens resultou em apenas uma planta por explante, enquanto o emprego de ápices com várias folhas resultou em taxa regenerativa mais elevada. Zaffari et al. (1995) observaram que a utilização de explantes grandes ( 7 a $8 \mathrm{~mm}$ ) da cv. Grand Naine resultou em um aumento na taxa regenerativa quando a gema, empregada como explante, foi seccionada longitudinalmente em duas partes e quando sofreu três incisões longitudinais eqüidistantes. Por outro lado, Lameira et al. (1988), trabalhando com as cvs. Prata e Nanicão, relataram que o tamanho do explante não influenciou no número de brotos formados.
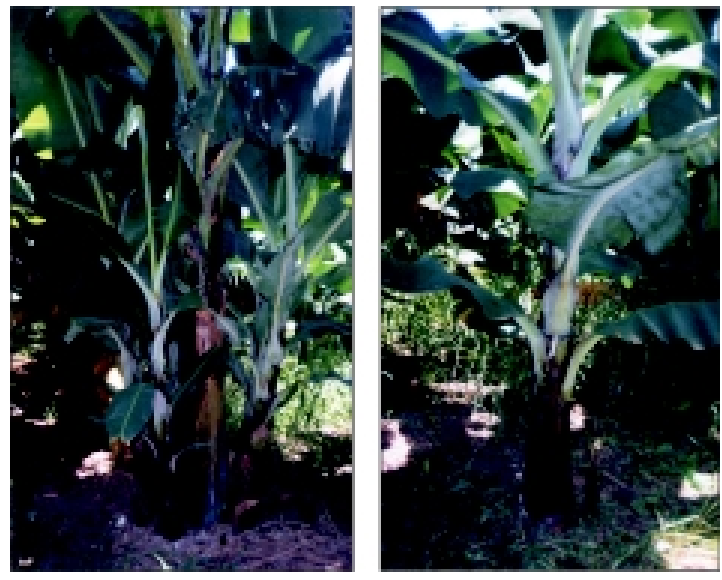

FIGURA 01 - Plantas de bananeira cv. Grand Naine, em condições in vivo, com graus diferenciados de dominância apical. ItajaíSC, 2001.

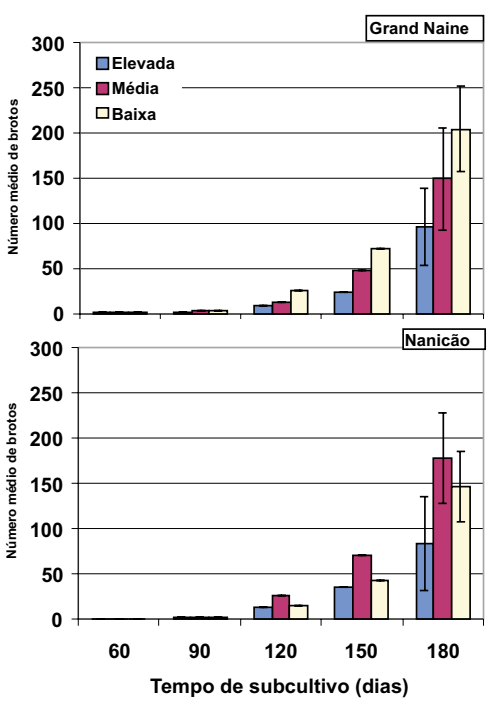

FIGURA 02 - Valores médios do número de brotos de bananeira cvs. Grand Naine e Nanicão cultivados in vitro, em meio de cultura MS, suplementado com AIA $(5,71 \mu \mathrm{mol} / \mathrm{l})$ e BAP $(4,44 \mu \mathrm{mol} / \mathrm{l})$, no $1^{\circ}$ subcultivo e de BAP $(11,1 \mu \mathrm{mol} / \mathrm{l})$ no $2^{\circ}, 3^{\circ}, 4^{\circ}$ e $5^{\circ}$ subcultivos. Barras verticais indicam o desvio-padrão (n=12). Itajaí-SC, 2001.

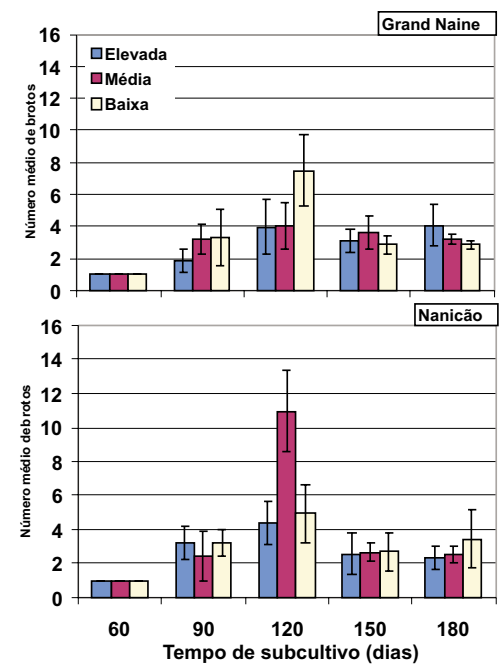

FIGURA 03 - Valores totais médios do número de brotos formados em rizoma de bananeira cvs. Grand Naine e Nanicão cultivados in vitro ao final dos cinco subcultivos, em meio MS suplementado com AIA $(5,71 \mu \mathrm{mol} / \mathrm{l})$ e BAP $(4,44 \mu \mathrm{mol} / \mathrm{l})$, no $1^{\circ}$ subcultivo e de $\operatorname{BAP}(11,1 \mu \mathrm{mol} / \mathrm{l})$ no $2^{\circ}, 3^{\circ}, 4^{\circ}$ e $5^{\circ}$ subcultivos. Barras verticais indicam o desvio-padrão $(\mathrm{n}=5)$. Itajaí-SC, 2001. 


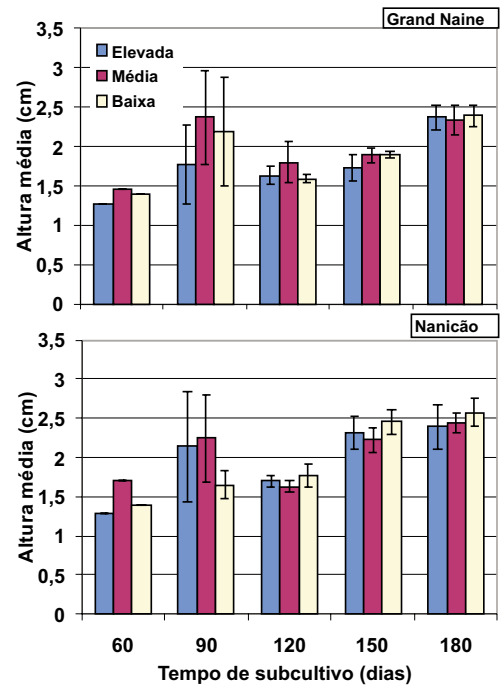

FIGURA 04- Valores médios da altura dos brotos de bananeira cvs. Grand Naine e Nanicão cultivados in vitro, em meio de cultura MS, suplementado com AIA $(5,71 \mu \mathrm{mol} / \mathrm{l})$ e BAP $(4,44 \mu \mathrm{mol} / \mathrm{l})$, no $1^{\circ}$ subcultivo e de BAP $(11,1 \mu \mathrm{mol} / \mathrm{l})$ no $2^{\circ}$, $3^{\circ}, 4^{\circ}$ e $5^{\circ}$ subcultivos. Barras verticais indicam o desviopadrão (n=12). Itajaí-SC, 2001.

TABELA 01 - Número médio e altura média dos brotos formados in vitro a partir de plantas-matrizes de bananeira cvs. Grand Naine e Nanicão, com diferentes graus de dominância apical, cultivadas em meio MS, adicionado de AIA $(5,71 \mu \mathrm{mol} /$ 1) e $\operatorname{BAP}(4,44 \mu \mathrm{mol} / \mathrm{l})$, no $1^{\circ}$ subcultivo e de $\operatorname{BAP}(11,1$ $\mu \mathrm{mol} / \mathrm{l})$ no $2^{\circ}, 3^{\circ}, 4^{\circ}$ e $5^{\circ}$ subcultivos. Itajaí-SC, 2001.

\begin{tabular}{|c|c|c|c|c|c|c|c|c|}
\hline & \multirow{2}{*}{\multicolumn{4}{|c|}{$\frac{N^{\circ} \text { médio de brotos formados }}{\text { Dominância Apical }}$}} & \multirow{2}{*}{\multicolumn{4}{|c|}{$\begin{array}{c}\text { Altura média dos brotos formados } \\
\text { Dominância Apical }\end{array}$}} \\
\hline & & & & & & & & \\
\hline & Elevada & Dominancia Apical & Baixa & & Elevada & Mil & Baixa & \\
\hline & \multicolumn{8}{|c|}{$1^{\circ}$ subcultivo $(60$ dias $)$} \\
\hline Grand Naine & 1.00 & 1.00 & 1.00 & NS & 1.27 & 1.46 & 1.39 & NS \\
\hline \multirow[t]{2}{*}{ Nanic o } & 1.00 & 1.00 & 1.00 & NS & 1.28 & 1.70 & 1.38 & NS \\
\hline & \multicolumn{8}{|c|}{$2^{\circ}$ subcultivo (90 dias) } \\
\hline Grand Naine & $1.87 \mathrm{~b}$ & $3.22 \mathrm{a}$ & $3.33^{\mathrm{a}}$ & $*$ & 1.77 & 2.37 & 2.19 & NS \\
\hline \multirow[t]{2}{*}{ Nanic o } & 3.20 & 2.43 & 3.20 & NS & 2.14 & 2.24 & 1.65 & NS \\
\hline & \multicolumn{8}{|c|}{$3^{\circ}$ subcultivo (120 dias) } \\
\hline Grand Naine & $3.96 \mathrm{~b}$ & $4.01 \mathrm{~b}$ & $7.51^{\mathrm{a}}$ & $*$ & $1.63^{\mathrm{a}} \mathrm{b}$ & $1.80 \mathrm{a}$ & $1.59 b$ & * \\
\hline \multirow[t]{2}{*}{ Nanic o } & $4.40 \mathrm{~b}$ & $10.96 \mathrm{a}$ & $4.95 \mathrm{~b}$ & $* * *$ & $1.70^{\mathrm{a} b}$ & $1.63 \mathrm{~b}$ & $1.77 \mathrm{a}$ & $*$ \\
\hline & \multicolumn{8}{|c|}{$4^{\circ}$ subcultivo (150 dias) } \\
\hline Grand Naine & 3.11 & 3.60 & 2.85 & NS & $1.73 \mathrm{~b}$ & $1.89 \mathrm{a}$ & $1.90 \mathrm{a}$ & $* *$ \\
\hline \multirow[t]{2}{*}{ Nanic o } & 2.56 & 2.67 & 2.68 & NS & $2.31^{\mathrm{a}} \mathrm{b}$ & $2.22 \mathrm{~b}$ & $2.46 \mathrm{a}$ & $*$ \\
\hline & \multicolumn{8}{|c|}{$5^{\circ}$ subcultivo (180 dias) } \\
\hline Grand Naine & $4.10 \mathrm{a}$ & $3.19 \mathrm{~b}$ & $2.85 b$ & ** & 2.37 & 2.34 & 2.39 & NS \\
\hline Nanic o & $2.32 \mathrm{~b}$ & $2.50 \mathrm{ab}$ & $3.43^{\mathrm{a}}$ & $*$ & 2.39 & 2.44 & 2.57 & NS \\
\hline
\end{tabular}

Médias seguidas da mesma letra, na mesma linha, não diferem estatisticamente entre si pelo teste de Tukey 5\%. (NS não significativo, $* \mathrm{p}<5 \%$, $* * \mathrm{p}<1 \%, * * * \mathrm{p}<0,01 \%$ ).

TABELA 02 - Número médio do total de brotos formados em rizoma de bananeira cvs. Grand Naine e Nanicão cultivados in vitro ao final dos cinco subcultivos, em meio de cultura MS, suplementado com AIA $(5,71 \mu \mathrm{mol} / \mathrm{l})$ e BAP $(4,44 \mu \mathrm{mol} / \mathrm{l})$ no $1^{\circ}$ subcultivo e de BAP $(11,1 \mu \mathrm{mol} / \mathrm{l})$, no $2^{\circ}, 3^{\circ}, 4^{\circ}$ e $5^{\circ}$ subcultivos. Itajaí-SC, 2001.

\begin{tabular}{lllll}
\hline \multirow{2}{*}{ Cultivar } & \multicolumn{3}{l}{ Dominância Apical } & \\
\cline { 2 - 4 } Grand Naine & $86.45 \mathrm{~b}$ & $141.76 \mathrm{ab}$ & $151.50 \mathrm{a}$ & $*$ \\
Nanic o & $92.55 \mathrm{~b}$ & $143.96 \mathrm{a}$ & $108.88^{\mathrm{a}} \mathrm{b}$ & $*$ \\
\hline
\end{tabular}

Médias seguidas da mesma letra, na mesma linha, não diferem estatisticamente entre si pelo teste de Tukey $5 \%$. (NS não significativo, $* \mathrm{p}<5 \%$, ** $\mathrm{p}<1 \%$, *** $\mathrm{p}<0,01 \%)$.
Em relação aos valores médios acumulados do número de brotos formados ao longo dos subcultivos, notou-se um efeito favorável do tratamento com baixa dominância apical para a cv. Grand Naine, apresentando ao final dos subcultivos um número médio de 141,76 brotos. Já, para a cv. Nanicão, o tratamento com média dominância apical resultou em uma taxa média de proliferação de 143,96 brotos.

Os explantes provindos do tratamento com elevada dominância apical resultaram em valores médios inferiores para este parâmetro: 86,45 e 92,55, para as Cvs. Grand Naine e Nanicão, respectivamente. Segundo Jarret (1986), são significativas as variações em relação à capacidade proliferativa in vitro dentre as cultivares de banana. Ao final de cinco subcultivos, Sandoval et al. (1991) obtiveram valores acumulados médios de 95 brotos por explante para a cv. Curraré; 211 para a cv. Dominico; 366 para a cv. Gran Enano e 93 para a cv. Valery. Já Oliveira \& Silva (1997) obtiveram médias de 189,2 para a cv. Nanicão e 198,8 para a cv. Grand Naine e Oliveira et al. (1999) obtiveram 69,19 para a cv. Nanicão e 68,38 para a cv. Prata-Anã.

As variações quanto à capacidade de proliferação in vitro da bananeira podem ocorrer de forma significativa até mesmo entre clones de uma mesma cultivar (Sandoval et al., 1991). Mendes et al. (1996), trabalhando com nove clones da cv. Nanicão, obtiveram valores diferenciados quanto ao número médio de brotos formados por explante ao final de seis subcultivos, tendo o clone mais produtivo apresentado um valor médio de 1.850 brotos enquanto o menos produtivo apenas 143 brotos.

A formação de gemas laterais é um processo de organogênese direta comandado pela dominância apical, na presença de um balanço AIA/Cks pró Cks (Skoog \& Miller, 1957). Por sua vez, a dominância apical é o controle exercido pelo ápice da parte aérea sobre o crescimento das gemas laterais, ramos e folhas, sendo influenciado, em diferentes graus, por fatores ambientais, genéticos e fisiológicos (Ma \& Smith, 1992; George, 1996). Pode-se inferir que os resultados obtidos no presente trabalho se relacionam diretamente ao conteúdo hormonal (AIA/ Cks) endógeno das mudas in vivo e à dominância apical, com reflexos diretos no controle da morfogênese das gemas laterais e, conseqüentemente, nas taxas proliferativas in vitro. Sugere-se, assim, que as mudas com uma baixa e/ou média dominância apical in vivo apresentariam um balanço hormonal endógeno favorável às citocininas, aspecto este que parece ser um dos principais fatores estimulatórios à formação de gemas laterais e seu posterior desenvolvimento.

Para o parâmetro altura, observou-se uma relação inversamente proporcional à taxa proliferativa, ou seja, quanto maior a altura média, menor foi o número médio de brotos formados. Estes resultados coincidem com os observados por Zaffari (1998) com a cv. Grand Naine. As maiores alturas foram observadas em brotos crescidos no tratamento com baixa dominância apical e aos 180 dias de cultivo ( $5^{\circ}$ subcultivo), apresentando alturas de 2,39 $\mathrm{cm}$ para cv. Grand Naine e de 2,57 cm para cv. Nanicão.

Durante o período de aclimatização, as plantas micropropagadas foram avaliadas visualmente em relação ao fenótipo, não revelando a presença de variantes somaclonais. Resultados idênticos foram relatados por Rodrigues (1996), Oliveira \& Silva (1997) e Oliveira et al. (1999). Segundo Israeli et al. (1991), o emprego de até seis subcultivos para a micropropagação da bananeira resulta em taxas percentuais de variantes somaclonais que não ultrapassam os 5\%. Rodrigues (1996) relatou que o aumento no número de subcultivos aumenta a taxa de variação somaclonal em mudas de bananeira micropropagadas das cultivares Grand Naine e Nanicão.

A dominância apical in vivo parece estar relacionada diretamente com o comportamento posterior dos explantes in vitro. Assim, as avaliações do comportamento das diferentes fontes de explantes revelaram resultados positivos em favor da utilização de mudas de plantas com média e baixa dominância apical, para as cvs. Nanicão e Grand Naine, respectivamente. No entanto, fica difícil estabelecer uma correlação precisa entre eles, uma vez que a variabilidade da capacidade de proliferação é vista de forma significativa entre cultivares e até mesmo entre 
clones de uma mesma cultivar.

Tem sido sugerida uma relação entre o nível de dominância apical e o conteúdo hormonal endógeno dos explantes no que diz respeito ao balanço AIA/Cks. Em estudos hormonais endógenos em rizomas de bananeira in vitro, Zaffari (1998) relatou um balanço AIA/Cks favorável às Cks, em materiais que proliferavam com maior intensidade. Assim, a utilização de explantes provindos de plantas-mães em estágios de baixa e média dominância apical resultou na obtenção de um maior número de plantas micropropagadas ao final dos subcultivos, uma vez que estes explantes, provavelmente, apresentavam um balanço hormonal endógeno de AIA/Cks favorável ao desenvolvimento de brotos laterais.

\section{CONCLUSÕES}

1 - O grau de dominância apical in vivo de plantas de bananeira cvs. Grand Naine e Nanicão influenciou diretamente o comportamento posterior in vitro dos explantes, no que diz respeito à capacidade proliferativa. 2 - A utilização de mudas oriundas de plantas matrizes com baixo grau de dominância apical in vivo proporcionou a maior taxa média proliferativa $(7,51)$ para a cv. Grand Naine.

3 - Mudas oriundas de plantas matrizes de bananeira com grau médio de dominância apical in vivo resultaram na maior taxa média proliferativa $(10,96)$ para a cv. Nanicão

4 - O ponto máximo de proliferação dos explantes in vitro foi observado no terceiro subcultivo.

5 - A maior média total de brotos micropropagados ao final dos cinco subcultivos (180 dias) foi de 141,76 para a cv. Grand Naine em explantes oriundos de plantas-matrizes de bananeira com baixo grau de dominância apical in vivo.

6 - Para a cv. Nanicão, a maior média total de brotos micropropagados ao final dos cinco subcultivos foi de 143,96 para explantes oriundos de plantas-matrizes de bananeira com grau médio de dominância apical in vivo.

7 - As avaliações fenotípicas não revelaram a presença de variantes somaclonais do tipo anão e variegado.

\section{REFERÊNCIASBIBLIOGRÁFICAS}

ANGARITA, A.; PEREA, M. Micropropagación de plátanos y bananos. In: ROCA, W.M; MROGINSKI, L.A. Cultivo de tejidos en la agricultura. Cali: CIAT, 1991.p. 495-512

BANERJEE, N.; DE LANGHE, E. A tissue culture tecnique for rapid clonal propagation and storage under minimal growth conditions of Musa. Plant and Cell Reports, Berlin, v.4, n.6, p.351-354, 1985.

CLINE, M.G. Concepts and terminology of apical dominace. American Journal Botanic, Columbia, v.84, n.8, p.1064-1069, 1997.

GEORGE, E.F. Plant Propagation by Tissue Culture. Part 1 and 2. England. 1996.

ISRAELI, Y.; REUVENI, O.; LAHAV, E. Qualitative aspects of somaclonal variations in banana propagated by in vitro techniques. Scientia
Horticulturae, Amsterdan, v.48, p.71-88, 1991.

JARRET, R. L. In vitro propagation and concervation of bananas and plantains. In: IBPGR Advissory Committee on in vitro Storage, Report of the meeting (Appendix). Roma, Italy, 1986.

LAMEIRA, O.A.; PINTO, J.E.B.P.; PASQUAL, M. Efeito do tamanho do explante no desenvolvimento in vitro da bananeira (Musa acuminata Colla) cultivares prata e nanicão. Ciência Prática, Lavras, v.12, n.2, p.207-211, 1988

MA, B.L.; SMITH, D.L. Modification of tiller productivity in spring barley by aplication of chlorequat or ethephon. Crop Science, Madison, v.32, n.3, p.735-740, 1992.

MANTEDIOCA, S. Estudo sobre o controle da brotação das gemas epífilas em Bryophyllum calycinum. 126f. Tese (Doutorado) Universidade de Campinas, Campinas, 1996.

MENDES, B.M.J.; MENDES, F.J.; NETO, A.T.; DEMETRIO, C.G.B.; PUSKE, O.R. Efficacy of banana plantlet production by micropropagaation. Pesquisa Agropecuária Brasileira, Brasília, v.31, n.12, p.863-867, 1996.

MURASHIGE, T.; SKOOG, F. A revised medium for rapid growth and bioassays with tobacco tissue culture. Physiologia Plantarum, Copenhagen, v.15, p.473-497, 1962.

OLIVEIRA, R.P.; SILVA, S.O. e. Avaliação da micropropagação comercial em bananeira. Pesquisa Agropecuária Brasileira, Brasília, v.32, n.4, p.415-420, 1997.

OLIVEIRA, R.P.; SILVEIRA, D.G.; OLIVEIRA, S.S.; SILVA, K.M.; VILARINHOS, A.D. Avaliação da micropropagação de genótipos diplóides, triplóides e tetraplóides de bananeira empregando protocolo utilizado em laboratórios comerciais. Revista Brasileira de Fruticultura, Cruz das Almas, v.21, n.3, p.269-273, 1999.

RODRIGUES, P.H.V. Efeito do número de subcultivos, na ocorrência de variação somaclonal, em mudas de bananeira micropropagadas, das cultivares Nanicão e Grand Nanine. Piracicaba, SP: USP, 1996. 104p.

SANDOVAL, J.A.F.; BRENES, G.G.; SANCHEZ, L.P. Micropropagación de platano y banano (Musa AAB, AAA) en el Catie. Turrialba, Costa Rica: Catie, 1991.29p.

SKOOG, F.; MILLER, C.O . Chemical regulation of growth and organ formation in plant tissues cultured in vitro. In: SYMPOSIA OF THE SOCIETY FOR EXPERIMENTAL BIOLOGY, 9., 1956, Aberystwyth. Procedings... p.118-131

TAMAS, I.A. Hormonal regulation of apical dominance. In: DAVIES, P.J. (ed.) Plant hormones: physiology, biochemistry and molecular biology. Dordrecht: Kluwer, 1995. p.572-597

ZAFFARI, G. Aspectos hormonais, estruturais e genéticos relacionados à micropropagação de gemas adventícias de Musa acuminata (AAA) cv. Grand Naine. 1998. 112f. Tese (Doutorado), Universidade de São Paulo, São Paulo, 1998.

ZAFFARI, G. R.; SOLIMAN FILHO, L. F.; TUKER, H. Efeito do tamanho do explante e da quebra da dominância apical sobre a brotação das gemas laterais na produção de mudas de bananeira in vitro. Revista Brasileira de Fruticultura, Cruz das Almas, v.17, n.1, p.37-42, 1995. 